\title{
Research on the Application of Electrical Automation in Electrical Engineering
}

\author{
Hongdai Si \\ School of Renewable Energy \\ Shenyang Institute of Engineering, \\ Shenyang, China \\ sihongdai@163.com
}

\author{
Xin Cheng \\ Shenyang Environmental Monitoring Center \\ Shenyang, China \\ chengx@163.com
}

\begin{abstract}
Nowadays the society is the age of information, the computer technology and network technology have been widely used in all walks of life, which effectively improve the competitive power of enterprises and promote the healthy development of the society. With the rapid development of economy, it also has made the corresponding electrical engineering technology progress, and the rapid development of electrical automation has a tremendous boost to the development of electrical engineering. With the popularity of electric automatic expanded, the application of electrical engineering is the corresponding recognition, driving the development of economy to play a promoting role in people's life. Electrical engineering is a public welfare undertakings in China, in order to make the synchronization with the social economy development, researchers also need to apply automation technology, so as to further build the industrialization society, realize the healthy development of social economy, and improve the quality of people's living standard and life. In this paper, researchers conduct a comprehensive analysis of the electrical engineering, its automation construction and development; its application is also analyzed correspondingly.
\end{abstract}

Keywords- Electrical Engineering; Automation; Application; Living Standard; Construction

\section{INTRODUCTION}

Since the reform and opening up, the social and economic development of China is a seismic, electrical engineering as an important foundation engineering in the development of society, people attach great importance to its development. In order to realize the automation level of electrical engineering, researchers will adopt a lot of automation technologies and information technologies, further promote the healthy development of the industrial society, and also improve the quality of people's living standard and life. However, under the influence of various aspects, the construction of the electrical engineering automation still has some problems, this article starts from the present situation of electrical engineering automation technology development, discusses the problems that exist in the electrical engineering automation construction, and proposes the corresponding solution measures.

\author{
Xiaopeng Cui \\ Benxi Power Supply Branch, State Grid Liaoning \\ Electric Power Supply Co., Ltd. \\ Benxi, China \\ cuixpjz@163.com
}

In the 1950s, the automation technology began to appear. With the constant progress of science and technology, automation technology has got great development and wide application. Within short decades from the original manual operation to a continuous production process, the progress of automation technology has brought great development[1]. The stability of the production process also put forward more strict requirements, and the instrument and meter are becoming more and more widely applied. The application of automation in the field of DCS technology is more extensive, the information technology greatly promoted the development of chemical technology, and the electrical automation technology is more widely used. Now automation is extensively applied in daily life, which has produced great influence on people's life and production. With the rapid development of science and technology, in order to further expand the scale of industry, the automation technology is confronted with increasingly high requirement.

Within the scope of the economic construction and people's life, the electrical automation technology has been applied in the largest scope, and the modern social life has brought earth-shaking changes, and electrical automation itself is more of course, which has to involve more extensive technology, involving information integrated processing and national security monitoring technology, and application of electrical automation of electrical engineering, the electrical engineering industry development is also a further promote role, based on comprehensive analysis of various materials electrical automation in the application of electrical engineering.

Traditional distributed control system of an information exchange of visits between the equipment, but it can reflect the entire electrical system of little amount of information, the operation and management of electrical system of the operator has a lot of inconveniences, if you can't use more convenient and faster system operation mode in the power plant, the accident that cannot be timely and accurate analysis of the reasons, find a effective solution in time, will cause a huge loss. Therefore, the electrical system needs to upgrade the automation level, instead of the traditional hard wiring a signal acquisition mode, uses the organic combination of a more intelligent 
way, build and perfect the electric power communication network system integration, practical electrical automation equipment and fieldbus system management level[2].

\section{THE CONSTRUCTION AND DEVELOPMENT OF ELECTRICAL ENGINEERING AND ITS AUTOMATION}

\section{A. The current development situation of electrical engineering automation technology}

In today's society of the information age, knowledge economy has replaced the growth of agriculture, industry, economy and computer technology, network technology, and the communication technology has been widely used in all walks of life, which has promoted the rapid development of social economy[3]. Electrical engineering is a foundation for the development of society, because its development will inevitably suffer, so researchers will use the various automation technology applications to a great extent, the closer the distance between the international. At present, with the continuous improvement of technical level, the technical staff began to all kinds of advanced system, network technology application in them, from all walks of life at this time the communication between the increasingly frequent, effectively promote the rapid development of social economy, achieve the data sharing resource, and improve the development of the electrical engineering automation technology. In addition, with all kinds of the application of automation technology and accelerate the industrialization society construction, and save the cost, improve the social and economic benefits. Automation technology in the application of electrical engineering is undoubtedly a major revolution.

\section{B. The problems existing}

In the development of modern society, enterprise and individual of quickening the pace of life, it also suggests that modern society is an efficient society, only in the practical work to improve efficiency, speed up the development, so as to adapt to the development of the society. In addition, in the process of electrical engineering automation construction, technical personnel need to adopt a more simple and convenient method, which can improve the automation level, but because of the many technical personnel do not to pay great attention to, or affected by various factors, in the process of building electrical engineering automation without reasonable analysis, this leads to the production of all kinds of problems in electrical engineering automation products, affect the normal development, is not conducive to the rapid development of social economy.

In modern social development, the technical personnel is not according to the actual situation of the electrical engineering automation system construction, that is to say, in the process of construction, its no reference, no pertinence, such construction products would not be able to meet the needs of modern enterprise, and even will increase cost, has caused great economic losses to the enterprise, is not conducive to the normal development of the enterprise, affect the sustainable development of social economy.

\section{Concrete measures for the construction of electrical engineering and its automation}

1) According to actual circumstances, establish a unified and platform of the system

In electrical engineering and its automation system construction and the design process, first of all requirements and technical personnel have the right ideas, before developing software, should try to understand to the actual situation, the needs of customers, and then through the scientific and reasonable planning work flow, so also can improve the efficiency of its construction, and construction cost control can be in the controllable range. In addition, the situation is different, thanks to the development of the enterprise technical personnel should demand for them to conduct a comprehensive analysis, and combine to create a unified and system platform, so also can save running cost for the enterprise to a great extent, improve the economic benefits of enterprises, promote the healthy development of the enterprise[4].

2) A data transmission interface standardization construction

Electrical engineering and its automation system can be efficient, fast, safe data transmission, but fully benefit from the standardization of its system programming interface. To use modern technology to solve the problem of program interface as soon as possible, in the concrete operation and the specific use for the connection of program interface is perfect, thereby reducing the time and cost of development engineering, electrical engineering and its automation system and office automation system of data exchange and sharing among powerful guarantee.

3) Establish common in electrical engineering and its automation system network structure

General network structure in various enterprises in the process of the implementation of industrial automation, equipment control system in manufacturing enterprises, technical regulation system, enterprise management system data between various systems to achieve efficient, fast, safe. The network structure is the electrical engineering and its automation is the most important part of the system. General network structure can also be the center of the control system and other communication management system for the configuration of the network resources, can make the information transfer correctly and on time, do the real traffic network structure.

4) Attach importance to the cultivation of professional talents of electrical engineering automation

Electrical engineering since as a traditional subject and one of the basic industry of national economy, but also obtained the very good development and attention. With the continuous development of world economy and the current situation of the shortage of energy, so they continue to talents to meet the needs of society. Solid professional basic requirement of fostering talents requires learning basic knowledge of natural science, grasping the humanities and social science and management science knowledge, and having strong ability of computer strain. Through the theoretical study, time, training and social practice, people cultivate comprehensive talents. The importance of play to practice, to train the innovative ability of development staff creativity is a very important ability, is also a kind of comprehensive ability [5]. In 
addition, the relevant professional practice training, it is a new development model, its purpose is to enhance the staff's practical and innovative ability, be divided into cognitive professional basic experiment, originally foundation, improvement, innovation of the four stages, allowing employees to combination of electrical and electronic measurement and experimental technology, electronic engineering practice, the microcomputer control and EDA experiment, the application of single-chip microcomputer integrated technology, the electronic circuit of the integrated design and so on comprehensive design experiment training.

\section{APPLICATIONS IN ELECTRICAL ENGINEERING}

\section{A. Design concept}

Using the design of remote monitoring method is applied to electrical engineering. Adopts the design of remote monitoring method, used in electrical engineering, it is limited within a certain range, but there are advantages at the same time also has the certain defect. This way of monitoring on the installation install economize economic spending, and reduce the cable number on it. This way of monitoring is reliable and easy to use. But this kind of remote monitoring methods, using range is limited, also only limited in small electrical engineering equipment, communications electrical factory is a very large amount of information, conflict with the remote monitoring equipment on the communication speed, thus causing the work limitations.

The design idea of the way of centralized monitoring is used in the electrical engineering.

Centralized monitoring design concept is to the individual features of the whole working system link each other on a processor work platform, although this kind of design idea is more simple, the maintenance and operation in the electrical engineering work is also very easy, and the influence of control station for centralized control program is not obvious, and all functions work together to have comprehensive workload increased processor, and its work will restrict the working speed of the whole system[6].

Common electrical equipment to monitor and control system, control object is increased at the same time, involved in the task for the host is very cumbersome, and this kind of situation to reduce, it is necessary to increase in cable investment, the corresponding increase in the number, it is worth noting that the extended due to the distance of the cable can cause bad influence factors, reduce the stability factor of the whole monitoring system.

Isolation and the auxiliary point on the wire connection is usually short circuit breaker. This will affect the electrical engineering equipment cannot work normally, if the connection belongs to secondary, its safety, security and maintainability are affected. Intricate connection can lead to numerical control system of the accident, so the centralized monitoring is applied more widely in electrical engineering.

\section{B. Fieldbus monitoring way involved in the design concept and in electrical engineering applications}

Fieldbus and the network of computer network information technology are used in the electrical automation system engineering, the wide range of usage, can be used to process accumulates more work information, so for electronic information technology of automation system in a promotion, the scope of application of electrical engineering and on site layout lines can be based on the condition of the distance properties of wire, and adopt different ways of plan, also to assess performance under the condition of the comprehensive function, the remote monitoring method has the advantage of the largest within the scope of application. In terms of electrical engineering, is to use computer networks to connect each other, and each unit is independent of each other, and the unique function, no matter which of device failure, to the device for repair, not only will not affect the whole network, for the whole network system will not damage, which not only improve the network performance of comprehensive system, also improved the reliability. Comprehensive the above information, the design concept of the in site monitoring ways in the application of electrical engineering

\section{THE APPLICATION OF AUTOMATION TECHNOLOGY IN THE ACTUAL SCOPE}

Application of automation technology in the factory is quite extensive. Automation technology in the application of the steel mills is shown in Fig.1

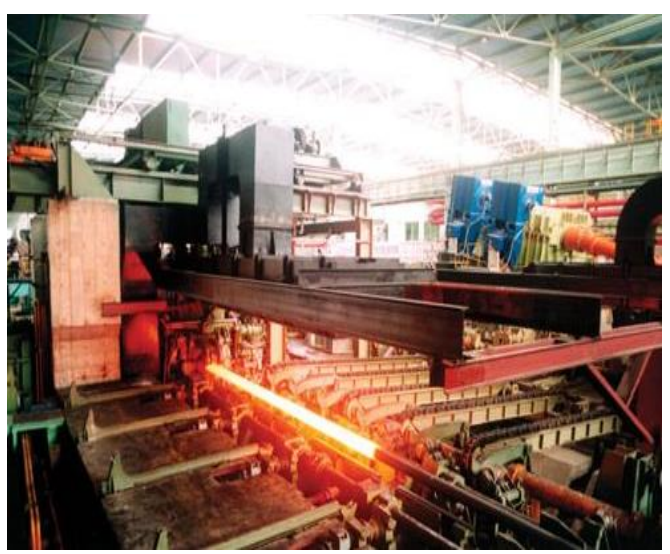

Figure 1. The application of the steel mills

\section{A. Power plant way of measurement and control system is dispersed system}

Distributed measurement and control system as the name suggests is working to realize the measurement and control. Mainly through hierarchical distribution in the form of work, to travel in the process of measurement and control of the workstation, data communication system, Ethernet and some related process supervision and project units [7]. Process monitoring and control unit in the measurement and control system of whole plays an important role, advantage is that it can be directly in the form of display for measurement and control system of work. First of all to the real-time receiving signals in the process of production, such as transformer signals, devices such as heat resistance, and can at the same time showing and printing system related equipment working conditions, this function allows staff in print data analysis and check the running status of equipment, more efficient and convenient. Automation technology in the application of power plant is shown in Fig. 2 


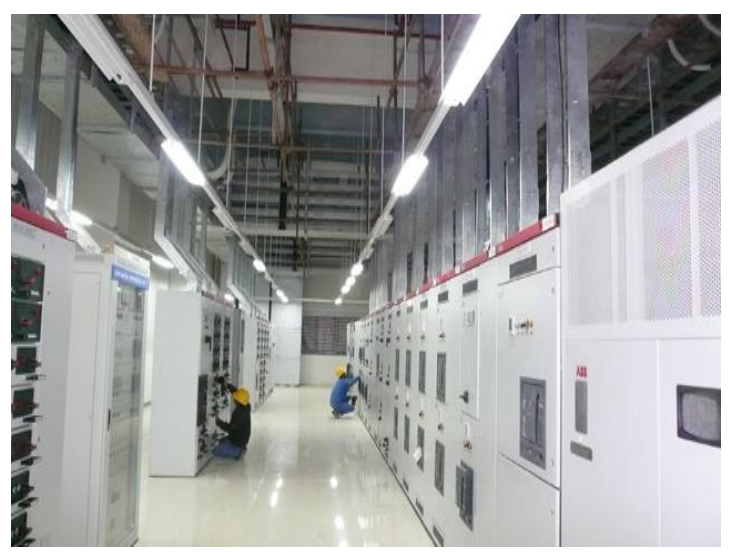

Figure 2. The application of power plant

\section{1) Smart}

With the progress of computer network, electrical automation system obtained greater development, and gradually to the intelligent direction for factory automation equipment development provides the basic premise. With the continuous development of electric automation technology, its actual application in the power plant monitoring devices, it will run state records in a storage device, associated with the actual operation, to avoid the great losses caused by unnecessary mistakes. Electrical automation system monitoring function, must implement the internal control, but also realized the external monitoring. Internal control refers to the regulation interval layer, is mainly responsible for dealing with some sudden fault summary and feedback of information. In the past, the need to send someone to do the power meter reading records, intelligent electrical automation system can realize automatic meter reading, greatly reduce the workload of staff, the power plant to improve the working efficiency. External monitoring mainly used for power generation power distribution unit, is responsible for the information and data transmission to the DCS system.

2) Related to automation technology and network technology closely

The introduction of Ethernet is the development trend of industrial modernization. Ethernet can use a faster speed, larger capacity, lower cost to complete information transmission, is widely used in various fields. Electric power sector and power plants to use more embedded Ethernet system [8]. The modern network technology ensures the smooth completion of the data exchange, which makes electrical automation run smoothly. In electrical automation system and the process of the combination of the network technology increasingly close, reduced the manpower, time and energy, save the cost.

3) Better use of foreign exchange control improve the efficiency of electrical automation

Conventional power station equipment system has failed to keep pace with the rapid development of electronic industry. To complete the high speed, efficient data integration task, researchers must use more of the switch control circuit. The foreign exchange control method can solve the final electrical equipment vibration and noise problem. Technology continues to improve, reduce noise, reduce the interference of electric automation equipment component, and thus greatly improve the efficiency of electrical automation. In short, the electrical automation technology and improved efficiency of power plant use the mechanical and electrical equipment, to ensure the security and stability of the equipment operation. At the same time, make the enterprise keep cost advantage in market competition, promote the overall development of the electric power company and power plants [9].

\section{B. The situation of the power grid scheduling analysis}

Power grid dispatching automation is important part of electrical engineering system, to realize the premise of power grid dispatching automation is first need to have to computer and can connect all equipment related devices and network, the second for grid scheduling server is required, must be able to display a large screen display mode and efficiency of the workstation.

\section{Substation work}

Traditional substation in the process of work is done by manual operation, such as from the monitor to the information feedback, data records, sorting and management, global monitoring substation under the premise of setting in the use of electromagnetic equipment by artificial to the finish. This traditional model has low efficiency and, error-prone faults, so the automation arises at the historic moment, and the implementation of substation automation system not only reduces the workload of operators but also reduces personnel, and greatly improves the overall economic benefit and work efficiency. The realization of the function of substation automation, not only changed in manual operation, also makes the related device has been improved, such as the traditional electromagnetic device is replaced by computer equipment. Substations can be implemented in the working process of the real-time visualization of monitoring work in this way, the staff work not only can quickly grasp the global, can also work through the computer data analysis of transformer substation possible problems, greatly improve work efficiency. Substation as the key part of electrical engineering, can say the practice of the automation technology to the good development of electrical engineering provides a qualitative leap [10].

\section{The distributed power/energy storage access}

National clean energy development strategy, how to make all kinds of distributed power supply connected to existing power system, has become a research topic for the electric power enterprises. Research on distributed power supply access technology is an action of energy conservation and emissions reduction on the support, for the next phase of parallel operation, monitoring and dispatching of the power station to provide a system, perfect technical reserves, train the ability of for distributed power plant monitoring, scheduling, lay a good foundation for the development of smart grid, at the same time will help you explore a promotion significance of technical solutions and management mode.

\section{CONCLUSION}

Within the scope of the national economic development in people's social and economic life, electrical automation technology has been employed in many ranges, because the modern social life has brought earth-shaking changes. Although the course contents 
related to the subject of electrical automation itself is more, the corresponding is more extensive in the application of the technology, not only involves the comprehensive information processing, in terms of national security monitoring technology has been applied, and electrical automation application of electrical engineering, play a role as support to the development of electrical engineering industry, also further promote in technology and other related aspects, based on comprehensive analysis of various materials within the electrical automation in the field of electrical engineering, the application of technology on a bit and shortcomings are analyzed. As an important technology of modern electrical engineering industry electric automation technology, only the application of positive, in the original technology innovation promotes the further development of electrical engineering.

\section{REFERENCES}

[1] J.Tang, J.Y.Mou. The use of automation technology in electrical engineering $[\mathrm{J}]$. Science and technology innovation and application. 2013, 63 (05):23-27.
[2] X.J.Lv, L.Wang. To investigate the electrical automation in electrical engineering through $[\mathrm{J}]$. Monograph of science and technology. 2012, 9(09):348-353.

[3] X.W.Du. Build on coal-fired power plant electrical automation system [J]. Value engineering .2012,.31(7).127-132.

[4] J.F.Wang. Thermal power plant electrical automation application study [J]. Science and technology association BBS, 2011, 38(12):20-21.

[5] J.H.Ma. Digital technology in the application of industrial electrical automation and innovation [J]. Journal of manufacturing automation. 2012, 12(6):76-80.

[6] F.Shi,D.Wang. The new development of substation automation system, introduction to digital substation automation technology [J]. Journal of Inner Mongolia petrochemical. 2009 ,21(2) : 126-130.

[7] Y.Guo, J.Zhou, Introduction to the smart grid integration mode of distribution network regulation [J]. Science and technology entrepreneurs, 2012,8 (11) : 121-125.

[8] Q.Zhang, The construction and development of electrical engineering and its automation [J]. Journal of China national foreign trade , 2011,14 (5) :394-396.

[9] X.H.Wang. Analyses the construction and development of electrical engineering and its automation [J]. Journal of electrical engineering,, 2009, 38(21): 19-21.

[10] Y.L.Wang. The application of electrical engineering and its automation $[\mathrm{J}]$. Journal of electrical engineering and its automation, 2009,33(20):7-12. 